\title{
O discurso de proprietários de academias sobre a prática da natação como atividade de lazer: inclusão ou elitização social?
}

Fabiano Pries Devide*

\begin{abstract}
A tentativa de buscar uma definição do lazer retrata 0 momento de construção teórica permanente em que esta área, como outras, se encontra.

\section{Resumo}

A presente investigação teve como objetivos: a) verificar como os professores do ensino da natação interpretam e manejam o acesso de praticantes e b) discutir o papel dos professores proprietários de academias de natação quanto à inclusão social da comunidade no aprendizado. Entrevistas com 5 professoras proprietárias de academias de natação permitiram considerar que: i) possuem uma clientela proveniente da classe média alta; ii) nunca ofertaram ou tiveram experiência em natação para a comunidade,- jii) consideram sua tarefa elitista,- iv) apontam a falta de piscinas públicas para o trabalho comunitário; v) justificam a inexistência de turmas para a comunidade à falta de parceria com outros órgãos, ao preconceito dos alunos pagantes e à falta de educação comunitária. Interpretamos que há fragilidade nos argumentos e um tênue comprometimento das proprietárias quanto à acessibilidade da natação enquanto atividade de lazer.
\end{abstract}

\section{Abstract}

The objectives of this study were: i) verify what the teachers who work with beginning swimming classes think about and how they manage the access of apprentices; and ii) discuss the function of the teachers who have their own swimming schools about the social inclusion of the community in the learning-how-to-swim process. Interviews with five teachers, owners of swimming schools have allowed us to conclude that: a) they have their customers from high middle class,b) they have never offered to or had experiences with offering swimming classes to the community,- c) they consider their task as elitist,-d) they point out the lack of public pools for community work,- and e) they justify the absence of classes to the community based on the lack of association with other institutions,- on the prejudice of regular pupils,- and on the lack of community education. In short, we interpret that there is some fragility in these arguments, and lack of compromise from the owners about the acessibility in the learning-how-to-swim process as a leisure activity.

\section{INTRODUÇÃO}

Na discussão ocorrida por ocasião do $5^{\circ}$ congresso Mundial do Lazer: lazer em uma sociedade globalizada - inclusão ou exclusão?, realizado na cidade de São Paulo (Brasil, 1998), a temática do lazer e do tempo livre foram discutidas, criticando-se o modelo industrial presente no sistema capitalista que, centrado no trabalho, tem educado as pessoas para a produção e não as prepara para saber desfrutar e administrar o seu tempo livre, conseqüência, entre outros fatores, da diminuição da jornada de trabalho e do desemprego estrutural causado pelo desenvolvimento tecnológico. Apontou-se para a necessidade de uma reorganização social e um 
redimensionamento do modelo econômico, deslocando o seu eixo central do trabalho para o tempo livre, no qual as atividades de lazer devem se tornar um elemento central na cultura de milhões de pessoas.

Ao final deste evento científico, elaborouse um documento, a Declaração de São Paulo, no qual, em seu artigo primeiro, o lazer surge definido como "o tempo em que temos autonomia e limites para buscarmos experiências significativas sem ferir as normas e valores da sociedade que valorizem o desenvolvimento social e individual". A tentativa de buscar uma definição do lazer retrata o momento de construção teórica permanente em que esta área, como outras, se encontra. Diante disto, não buscamos um conceito ou classificação a priori de lazer, pois o entendemos enquanto questão multidisciplinar, que sofre múltiplas abordagens. Estamos cientes da inexistência de um consenso, pois as discussões da área são infindáveis e trazem em seu bojo inúmeras definições. ${ }^{1}$

Neste contexto, para o presente estudo, após revisão de literatura, reconhecemos o lazer, em termos gerais, como um tempo caracterizado por sua propriedade liberatória, desinteressada, hedonística e pessoal (Dumazedier, 1973, 1979; Camargo, 1992; Mota, 1992; Marcellino, 1996), sendo desfrutado através da experiência de atividades escolhidas livremente (incluindo tanto aquelas que supõem o movimento, como o exercício físico; como aquelas que não o supõe, tal como a leitura).

Este tempo de lazer ocorre fora de um certo gênero de obrigações institucionais, impostas por organismos sociais; tem um caráter desinteressado, sem fins lucrativos, utilitários ou ideológicos; é desfrutado de acordo com os interesses de cada um, visando o desenvolvimento pessoal (Dumazedier, 1980; Camargo, 1992), podendo, em virtude de sua administração, constituir-se em um meio ou objeto de educação (Marcellino, 1990), ${ }^{2}$ e tendo, por fim, o seu acesso influenciado por aspectos políticos, econômicos, sociais, ambientais e culturais (Dumazedier, 1994; Bramante, 1998; Sader, 1998). ${ }^{3}$
A partir daí, consideramos, para fins deste estudo, a prática de atividade física sem fins competitivos como uma forma de lazer, sendo a natação uma dessas possíveis atividades. Atualmente observa-se uma maior oferta dessa atividade pelo aumento no número de academias, clubes e escolas e natação. Contudo, se investigarmos quem são os seus praticantes, constataremos que são provenientes, em sua maioria, das classes financeiramente mais abastadas da sociedade.

Considerando que a prática da atividade física, enquanto atividade de lazer, é limitada por uma série de fatores externos ao indivíduo (Faria Júnior, 1991) servindo muitas vezes como símbolos de distinção de classes (Soares, 1994; Marcellino, 1995), e reconhecendo o crescente número de academias de natação que vem surgindo nas cidades, procuramos investigar as representações sociais dos profissionais proprietários de academias de natação a respeito da possibilidade de acesso à sua prática, e da sua atuação para uma possível viabilização da natação para a comunidade.

\section{CONSTRUÇÃO DO ESTUDO}

Diante de tais pressupostos, o presente estudo teve como objetivos principais, investigar como os profissionais de Educação Física, proprietários de academias de natação i) representam a acessibilidade dessa atividade pela comunidade, e ii) as possíveis soluções oferecidas por eles para que haja uma viabilização da natação enquanto atividade de lazer.

Para contemplar estes objetivos, uma série de fatores que tendem a influenciar as representações sociais destes profissionais foram investigados, entre eles o local de formação; o enfoque dado à natação no curso superior; os locais em que já trabalharam; e o tempo de trabalho com a natação, aspectos que, pensamos, interferem no discurso e nas práticas sociais desses profissionais, no momento em que administram suas respectivas instituições, contribuindo na construção de suas representações sociais acerca do acesso e viabilidade da prática da natação como atividade de lazer.

\author{
Nesse sentido, \\ o discurso, \\ aspecto focali- \\ zado para fins \\ desse estudo, \\ revela condi- \\ ções estrutu- \\ rais, sistemas \\ de valores e \\ normas que, \\ por meio de um \\ porta-voz \\ (enunciador), \\ apresenta as \\ representações \\ de determinada \\ sociedade \\ discursiva \\ (Foucault, \\ 1996) em \\ condições \\ sócio- \\ históricas \\ definidas, \\ balizadas pelas \\ respectivas \\ formações \\ discursivas e \\ ideológicas \\ (Pechêux, \\ 1995; Fiorin, \\ 1995).
}




\section{O motivo mais saliente na escolha da profissão foi o envolvimento e o prazer pela atividade física, além da identificação pessoal com a área da Educa- ção Física. A maioria teve uma formação generalista \\ (Faria Júnior, 1987).}

A premissa acima se justifica no sentido de que as opiniões, valores e crenças que constituem as representações sociais dos profissionais proprietários devem se remeter ao contexto em que possivelmente surgiram, como por exemplo, nos cursos de graduação, nos ambientes de trabalho, e nas múltiplas interações sociais com outros sujeitos ou meios de comunicação, onde circulam saberes relacionados à acessibilidade à prática esportiva e sua viabilização. Estas informações auxiliam na interpretação do seu discurso, tornando necessário investigar aqueles fatores que podem direta ou indiretamente contribuir para que eles apresentem determinadas posições em relação à questão central do estudo: as representações acerca da acessibilidade e da prática da natação pela comunidade.

Em decorrência de nossa vivência atuando na área da natação, formulamos algumas questões específicas com respeito à forma como o acesso à prática da natação é concebida pelos profissionais proprietários de academias: a) Como representam o acesso à prática da natação?; e b) Qual a sua contribuição, enquanto proprietários, na viabilização da natação enquanto atividade de lazer para a comunidade?

A relevância do estudo reside no fato de permitir uma reflexão da posição de profissionais de Educação Física, proprietários de academias de natação, em relação ao acesso e à viabilização da prática dessa atividade para a comunidade de baixo nível sócio-econômico, considerando o que se tem feito para que isso se concretize.

Para contemplar nossos objetivos, realizamos entrevistas semi-estruturadas (Richardson, 1985) com cinco professoras, proprietárias de academias na região serrana do estado do Rio de Janeiro. O motivo da escolha por este grupo deu-se pela curiosidade de saber se esses profissionais desenvolvem algum trabalho de natação com a população de baixo poder aquisitivo, uma vez que, sendo proprietárias, possuem maiores possibilidades e autonomia para a abertura de um espaço para a comunidade em sua academia de natação.
Após a realização das entrevistas, as transcrevemos, na íntegra, para posterior leitura e análise discursiva, quando buscamos versões de contraste que emergem no discurso das informantes, retratando a construção do sentido no dialogismo (Bakhtin, 1995; Spink, 1996; Brait, 1997); as características pragmáticas da linguagem (Rorty, 1994; Costa, 1994); detalhes significativos como silêncios e hesitações (Orlandi, 1996); a organização do discurso no sentido da argumentação; a polifonia (Maingueneau, 1997) e a polissemia (Pechêux, 1995) discursivas.

\section{REFERENCIAL TEÓRICO-METODOLÓGICO}

Para a análise e interpretação do discurso das informantes, utilizamos as abordagens teórico-metodológicas das Representações Sociais e da Análise do Discurso. Para Moscovici (1978) e Jodelet $(1989,1998)$, as representações sociais são um saber elaborado na interação cotidiana. Estas representações se articulam na vida coletiva com estratégias desenvolvidas pelos sujeitos para entender o quotidiano. São referências de alguém sobre alguma coisa (do sujeito em relação ao objeto representado), com caráter imaginativo, construtivo, e de natureza social, pois os seus elementos articulam e provêm de um saber compartilhado, influenciando as práticas sociais e sendo retroalimentadas por estas (Rouquette, 1998; Wagner, 1998).

Os processos e condições ${ }^{4}$ que afetam, constituem e contribuem para a gênese das representações sociais estão co-relacionados com a comunicação e as práticas cotidianas ${ }^{5}$ dos atores sociais. Nesse sentido, o discurso, aspecto focalizado para fins desse estudo, revela condições estruturais, sistemas de valores e normas que, por meio de um porta-voz (enunciador), apresenta as representações de determinada sociedade discursiva (Foucault, 1996) em condições sócio-históricas definidas, balizadas pelas respectivas formações discursivas e ideológicas (Pechêux, 1995; Fiorin, 1995).

Para Bakhtin (1995), a palavra é o modo mais puro pelo qual se pode observar a relação 
social, onde encontram-se os valores contraditórios entre grupos sociais. Logo, a mediação e circulação das representações sociais se dá principalmente através da linguagem (Moscovici, 1978; 1995; Madeira, 1998). As representações sociais, desta forma, constituem-se em elementos para a análise das condições sociais de determinados grupos, refletindo as facetas da realidade de acordo com a sociedade discursiva da qual provém, aqui representada pelas profissionais de Educação Física proprietárias de academias de natação.

Neste sentido, sugerimos que as representações sociais que esses atores têm em relação ao acesso à prática da natação e sua viabilidade, são um reflexo de suas posições no mercado de trabalho, de sua formação profissional, de suas experiências com a natação, de sua interlocução com outros profissionais, de sua memória discursiva, entre outros fatores, pois o comportamento e o pensamento delas só significarão, se interpretados nos limites estabelecidos por suas condições sociais. Portanto, é em decorrência de seu contato com o quotidiano, através de interações sociais, que cada profissional constrói significados, idéias, símbolos, valores, crenças ou, como denominamos aqui, representações sociais a respeito da questão do acesso e viabilidade da prática da natação, objeto de nosso estudo.

\section{RESULTADOS}

Apresentamos como resultado, algumas características relevantes das informantes e, posteriormente, nos concentramos em analisar o discurso a respeito de suas posições sobre o acesso e à viabilização da natação em academias como atividade de lazer.

\section{SOBRE AS COLABORADORAS}

As informantes são professoras e proprietárias de academias de natação na região serrana do Rio de Janeiro. Todas possuem licenciatura plena em Educação Física, com um tempo médio de formação de dez anos em instituições públicas e privadas. Trabalham com natação a cerca de oito anos, ${ }^{6}$ tendo a natação como atividade principal de atuação profissional. Não possuem experiência com projetos comunitários de Educação Física que incluíssem a natação. $\mathrm{O}$ motivo mais saliente na escolha da profissão foi o envolvimento e o prazer pela atividade física, alérñ da identificação pessoal com a área da Educação Física. A maioria teve uma formação generalista $^{7}$ (Faria Júnior, 1987). Contudo, apesar da formação eclética, as informantes se deparam com diversas dificuldades para adequarem-se à realidade social em que estão inseridas, em decorrência da superficialidade dos conteúdos apresentados na graduação, levando-as a buscarem nos cursos de extensão, o aprofundamento necessário.

Algumas informantes afirmaram que o enfoque da disciplina natação foi para o lado pedagógico do ensino: "a visão da natação foi bastante diferente (...) Acho que foi mais com o ensino" (Patrícia). No entanto, outras informantes criticaram a disciplina, por ser direcionada à parte técnica, histórica e de performance em detrimento do ensino: "aulas eminentemente práticas... com (...) um conteúdo pra você aprender a dar aula (...) mínimo" (Sandra).

Sobre a avaliação na disciplina, algumas professoras disseram que era feita através de micro-aulas ministradas aos próprios alunos, com enfoque na metodologia de ensino: "(...) a avaliação era... voltada pra parte teórica, pra parte prática e, e... pra parte... da metodologia de ensino (...)" (Patrícia). Mas todas os informantes apontaram o fato da prova prática exigir, com diferentes magnitudes, que o acadêmico nadasse os quatro estilos, dominasse as saídas e viradas, o que gerou críticas contundentes por parte de Fernanda: "a prova prática, um absurdo. (...) tinha que avaliar (...) se você explica bem os conteúdos. (...) é mais válido fazer uma prova prática desse modo do que fazer uma (...) avaliando... a nossa performance".

A preocupação central da disciplina com o desempenho dos futuros profissionais em relação ao domínio e à execução perfeita dos nados, saídas e viradas, leva-nos a interpretar que a discussão sobre aspectos econômicos, sociais
Os interesses que

levam as informantes a atuarem com natação são o contato com o meio aquático e seus beneficios, $e$ a identificação pessoal com a atividade. 
e culturais relacionados ao acesso e à prática da natação foi construída principalmente no dialogismo da interação com o pesquisador (Bakhtin, 1995; Spink, 1996), uma vez que não fizeram parte da formação profissional das informantes.

Consideramos relevante saber em quais

No que concerne ao lazer, autores como Marcellino (1995)e Sader (1998) enfatizam o caráter de distinção de classes que tangencia a gama de oportunidades para a prática de atividades de lazer no tempo livre da população hoje, em função da construção das

barreiras sociais $e$ econômicas interclasses.

ambientes as professoras já desenvolveram atividades com natação, além das suas respectivas academias. Neste aspecto, o local de atuação predominante ainda foi a academia, com domínio da atuação iniciação e aperfeiçoamento em natação. ${ }^{8} \mathrm{O}$ predomínio desses locais privados (academias de natação) supõe a necessidade do poder aquisitivo dos alunos para freqüentá-los, e com isso, a inviabilidade da prática da natação pela comunidade. Isto nos leva a inferir que, desde a sua formação, essas proprietárias atuam com camadas privilegiadas da sociedade, aspecto confirmado por elas.

Os interesses que levam as informantes a atuarem com natação são o contato com o meio aquático e seus benefícios, e a identificação pessoal com a atividade. Sandra posiciona a natação como tão importante quanto aprender a andar: "é uma coisa tão importante como (...) a criança engatinhar, (...) andar, como a criança aprender a comer sozinha...". O seu discurso, equiparando o ato de aprender a nadar com a aprendizagem do caminhar e da autonomia, reforça o pensamento antigo de Platão de que o homem que não sabia nadar era tão desprezível quanto aquele que não sabia ler (Catteau \& Garoff, 1990).

Além disto, há uma tendência das informantes em supervalorizar a natação como melhor atividade física para a saúde. Devide e Ferreira (1997) sugerem que uma representação social ancorada na crença causai entre a prática do exercício e a saúde começa a construir-se no quotidiano e se consolida na formação em cursos de graduação em Educação Física. De fato, se nos remetermos à história, encontramos uma forte influência militar e médico-higienista que utilizou a Educação Física respectivamente com fins de eugenização e higienização da sociedade (Costa, 1983; Soares, 1994; Betti, 1995; Car- valho, 1995). Tal crença tende a estabelecer uma relação causal entre estas esferas, pautando-se em uma falsa consciência que impõe ao indivíduo a responsabilidade da prática de exercícios para a manutenção da saúde individual, desconsiderando as barreiras para que essa prática se efetue (Faria Júnior, 1991; Marcellino, 1995; Devide, 1996). Tais influências históricas, ainda presentes nos cursos de graduação, devem ser consideradas para se entender os motivos contribuintes para as informantes adotarem um discurso supervalorativo em relação à natação.

\section{COM A PALAVRA, AS PROFESSORAS}

E PROPRIETÁRIAS...

Para investigar as opiniões das informantes em relação à elitização da natação na sociedade brasileira, perguntamos como concebiam a possibilidade de acesso à sua prática e a possível função que o profissional que trabalha com a natação, proprietário de academia, poderia desempenhar para viabilizar este espaço para o acesso da natação pela comunidade.

Segundo as informantes, a maioria dos alunos que freqüentam as aulas em suas academias são provenientes de classes financeiramente abastadas. Diante deste quadro, as professoras consideram a natação uma atividade elitista: "a natação acaba sendo um pouquinho elitista (...). Acaba sendo de luxo. (...) eu nem preciso selecionar o meu aluno, porque, uma pessoa que não tiver recurso, ela vai vir aqui, vai ver o meu preço, ela não vai entrar. Então acaba sendo elitista". (Ana)

É clara a construção do sentido no discurso de Ana. No início da fala, ao discorrer sobre a natação, quando ela utiliza o advérbio "um pouquinho" e posteriormente o adjetivo "luxo". Ao final, utilizando o operador argumentativo "Então" Ana conclui e fortalece sua opinião sobre a elitização da atividade.

De fato, a elitização da natação tem raízes históricas que não podem ser desconsideradas. Soares (1994) aponta diferenças entre as atividades físicas das elites e das massas na se- 
gunda metade do século XIX. A elite, além da ginástica geral, realizava exercícios específicos que desenvolviam os sentidos, a elegância e as normas de conduta. Entre as atividades realizadas estavam a esgrima, a equitação, a dança e também a natação.

No que concerne ao lazer, autores como Marcellino (1995) e Sader (1998) enfatizam o caráter de distinção de classes que tangencia a gama de oportunidades para a prática de atividades de lazer no tempo livre da população hoje, em função da construção das barreiras sociais e econômicas interclasses.

Algumas informantes apontaram que, além da elitização, há falta de piscinas públicas para o desenvolvimento de um projeto comunitário, aspecto que, segundo elas, é determinante para a sua acessibilidade por parte da comunidade: "É bastante elitizada, é bastante restrita, até porque a gente não tem piscinas públicas (...) Então, ou você é sócio de um clube, ou você paga uma academia pra praticar a natação" (Patrícia). No seu discurso, ao utilizar a expressão "a gente", Patrícia assume a condição de algumas cidades, como o Rio de Janeiro, em relação à inexistência de locais públicos para a prática da natação, explicitando a necessidade do praticante vincular-se à instituições privadas para poder aprender a nadar.

Da mesma forma, Sandra estabelece comparações entre as cidades de Curitiba e Rio de Janeiro, enfatizando que a primeira possui piscinas públicas com programas comunitários, enquanto no Rio esta iniciativa se dá apenas a partir das universidades: "É como Curitiba. (...) Você vai numa praça, tem piscina pra comunidade (...) aberta ao público. (...) no Rio de Janeiro (...) você não tem uma! (...) É só dentro de uma universidade. (...). Que às vezes fazem pra comunidade".

De fato, é oportuno ressaltar a ausência de piscinas para a prática comunitária da natação. No Estado do Rio de Janeiro, primeiro a construir uma piscina olímpica no país (Lenk, 1942) e pioneiro na construção de uma piscina semi-olímpica na praia de Copacabana, não há piscinas para o uso comunitário. É conhecido o grande número de afogamentos nas praias do litoral da cidade, que poderia ser amenizado se trabalhos comunitários de ensino e conscientização sobre o ato de nadar fossem desenvolvidos com a população. ${ }^{9}$

Duas informantes focalizam a carência de piscinas especificamente nas escolas. Cláudia compara a situação do Brasil com a França: "Você vai numa França, onde você tem Liceus, onde na maioria das escolas têm... a natação é uma disciplina obrigatória das escolas. E no Brasil... (...) Quantas escolas têm, tem piscina?".

Fernanda abordou os locais públicos destinados à sociedade, muitas vezes desvalorizados e abandonados pelo governo, utilizando o exemplo das piscinas construídas nos CIEPs ${ }^{10}$ do Estado do Rio de Janeiro: "CIEP com piscina, virou... brejo. (...) CIEP com piscina maravilhosa que a gente sabe que existe por aí tá verde (...) e poderia ter aula de natação. As crianças pobres (...) poderiam ter, tá tendo aula e não têm".

Evidenciando a escassez de piscinas públicas como uma barreira para o acesso à natação, as informantes fornecem indícios de que há um reconhecimento e identificação das barreiras sociais para o acesso à prática esportiva como atividade de lazer. De fato, a escassez de equipamentos e espaços públicos que viabilizem a realização de atividades de lazer nas cidades é conhecida por todos. Diante desse quadro, acreditamos que, talvez, uma possível solução para a viabilização da natação para a comunidade possa partir da iniciativa privada.

Nesse sentido, perguntamos às informantes se possuíam ou cogitavam criar turmas comunitárias em suas academias. Não há turmas destinadas à comunidade nas academias. A maioria não cogita esta possibilidade, mas duas informantes refletiram sobre a questão afirmando que a falta de apoio, parceria e até espaço físico as impede de avançar projetos: "sabe o que eu penso? É que eu ia ter que ter uma pessoa em cada vestiário... pra (...) orientar a parte de higiene. Porque (...) essa é uma dificuldade grande

\section{Outra questão identificada no discurso das informantes foi a do preconceito dos alunos com relação às pessoas da comunidade utilizando as mesmas depen- dências que eles.}


pra ser trabalhada com uma faixa social inferior". (Cláudia)

Claudia diz que pensa dessa forma, porque a classe média que freqüenta a sua academia lhe proporciona problemas com a higiene dos vestiários. Ela estabelece uma relação causal entre o nível social dos alunos e os seus hábitos de higiene. Assim, afirma que para haver o trabalho comunitário, é necessário desenvolver a educação para a utilização do espaço da academia: piscina e vestiários.

\section{Para melhor}

interpretação, é relevante

ressaltarmos a

influência do

locus social do

enunciador na

construção do seu

discurso, que

fornece crenças,

valores, opiniões

que constituem

suas represen-

tações sociais $e$

são provenientes

da sociedade

discursiva da qual

faz parte

(Bakhtin, 1995;

Foucault, 1996;

Maingueneau,

1997).
Fernanda, outra proprietária afirmou que essa questão educacional contribui para o fechamento das portas das academias à comunidade, pois a crença identificada no discurso de Cláudia gera preocupações e "medo" nos proprietários com relação à higiene e à depredação da academia: "Falta educação. Então muita gente tem medo de abrir o negócio ao público e (...) entrarem, começar a destruir, não dar valor. Eu acho (...), ia ter que ter uma reeducação".

Outra questão identificada no discurso das informantes foi a do preconceito dos alunos com relação às pessoas da comunidade utilizando as mesmas dependências que eles. Ana e Sandra demonstram que isto se constitui numa barreira para a abertura desse espaço, uma vez que pode desencadear a evasão de alguns alunos.

\footnotetext{
Se entra uma pessoa aqui que eu sei que é carente (...) pode acontecer duas coisas: as outras mães que estão ali, que é aquele grupinho, vão acabar não gostando, ou vão tirar os alunos. Acaba acontecendo isso. E a sociedade mesmo. É aonde eu vivo. Acaba tendo essa discriminação (Ana).
}

Após o término da entrevista, Sandra depôs que poderia abrir uma turma para a comunidade, mas ciente que iria criar atrito com outros alunos que não gostariam de compartilhar a piscina com negros: "Eu tenho certeza que os pais dos alunos não iam querer ver a piscina cheia de negrinhos". Diante desse contexto, é necessário que o grupo se conscientize para não reforçar esse preconceito pois, na condição de proprietárias e diante da inexistência da iniciativa pública, estas professoras assumem um papel fulcral na viabilização de um espaço educativo para que a comunidade tenha acesso à prática da natação enquanto atividade de lazer.

Sandra deixa claro não cogitar abrir sua academia à pessoas de baixa renda quando, construindo o discurso, utiliza o operador "mas" para argumentar a falta de piscinas públicas para ela atuar com a comunidade: "Acho que se me procurassem pra isso, eu (...) poderia ter feito, mas não tem! Não tem uma piscina pública assim!".

Ao auxiliar a comunidade, as informantes tendem a assumir um discurso auto-valorativo, em que surgem como peças centrais para a organização de eventos, como no caso de Ana, que construindo o discurso em primeira pessoa, coloca-se à frente da academia, enquanto responsável pelo trabalho comunitário: "A única coisa que eu faço (...) pra comunidade, que eu vinculo a academia (...) a isso. Todo mês de julho a gente faz gincana com todos os alunos e (...) reúne tudo e dá pra comunidade (...). Sou eu indo pra lá, não de lá pegando a natação" (Ana).

Outra forma através da qual as informantes estabelecem um elo entre a academia e a comunidade, identificada no discurso, é o fornecimento de bolsas aos alunos. No entanto, as bolsas são destinadas àqueles que apresentam atestados de saúde que justifiquem um problema sério, em que a prática da natação possa funcionar como terapia, e que, no entanto, não podem custear as aulas. ${ }^{11}$

A gente tem vários bolsistas. A gente faz aquilo
que, que, que é pedido. Tem pessoas que chegam
e: '-Olha, não posso, meu filho é... tá com pro-
blema... grave'. Essa mãe (...) não tem condições
de pagar. Aí... a gente liberou a bolsa. Agora a
gente conseguiu fazer um apelo (...) Ela conseguiu
pelo INPS que pagassem. Foi ótimo pra gente. Eu
acho que tem que mais é dar esse apoio mesmo.
Foi ótimo pra mim que não tava recebendo nada e
comecei a receber (...). (Sandra)

Na primeira parte da fala de Sandra, o discurso é construído a partir da primeira pessoa do plural, representada pela academia. Pode-se identificar também um caráter "folclórico", no 
sentido de que o oferecimento das bolsas é tradicional nessas academias, além de um traço "assistencial", identificado a partir dos verbos "pedir" e "liberar", os quais sugerem que a academia está atendendo à solicitação da mãe carente, que, neste caso, representa a comunidade. Através do operador "Agora", Sandra desliza do tópico da cedência da bolsa para o da remuneração da mesma, modificando também o sujeito, agora na primeira pessoa do singular, representado por ela enquanto proprietária, que também se interessa pelo lucro da academia.

Ainda sobre a temática das bolsas, Ana concede o seguinte depoimento:

Se eu tiver uma pessoa que venha, que não tem recurso mas que tem problema sério desse, e você acha que a natação pode vir a ajudar, eu abro uma exceção. Essa pessoa vai ficar isenta. (...) tem que ser um problema bem justificado. (...) um problema de... saúde. Agora, abrir uma turma assim pra pessoas carentes, nunca passou.

Ana nunca cogitou utilizar a academia para desenvolver projetos com a comunidade. Observa-se no seu depoimento que o fornecimento de bolsa não é costumeiro, quando ela diz: "eu abro uma exceção". A carência financeira, por si só, também não é motivo para receber uma bolsa.

Patrícia, como Ana, fornece bolsas para aqueles alunos que apresentam problemas de saúde e são indicados por médicos a praticarem a natação: "Temos alguns, poucos, até por... por questões financeiras e de espaço. Mas temos alguns alunos com bolsa... por 'n' motivos: questões de saúde... Temos alguns alunos com, com bolsa".

Em um primeiro momento, o depoimento de Cláudia nos pareceu distinto dos demais, por fornecer bolsas não só para alunos com problemas de saúde, mas àqueles sem condições financeiras: "eu tenho essa coisa social, (...) a responsabilidade social (...), tanto é que eu lenho um percentual de alunos que não pagam (...). Não são pessoas que não pagam porque eu gosto não. São pessoas que não pagam porque não podem pagar". Entretanto, no transcorrer da sua fala, na interação com o entrevistador, ela tam- bém apresenta como aspecto determinante para a cedência da bolsa, a questão da saúde deficiente: "O meu papel é esse. Eu tenho um percentual de alunos, com problemas... respiratórios, ortopédicos que não pagam... É o mínimo que eu posso fazer... e é o que eu posso fazer no momento". (Cláudia).

Por fim, quanto ao papel do profissional de Educação Física, proprietário de academias de natação, na viabilização desse espaço para a comunidade, as informantes apontam a necessidade de parcerias, pois sozinhas não podem abrir suas respectivas academias para a comunidade, em função da falta de verbas: "Tem que ter alguma estrutura. É difícil a gente... né? Acho que a prefeitura, o governo, tinha que dar um apoio pra gente poder ajudar". (Ana)

Analisando o discurso das informantes, identificamos a polifonia como característica central, quando ora fala a voz da proprietária, ora a da professora e, em outros momentos, a voz da instituição (academia). Ana tende a utilizar sempre a primeira pessoa do plural, representada pela instituição, quando discursiviza. Sandra flutua entre as vozes da instituição e da proprietária; enquanto Cláudia, Patrícia e Fernanda enunciam na primeira pessoa do singular, com as vozes da proprietária e da professora da academia.

Para melhor interpretação, é relevante ressaltarmos a influência do locus social do enunciador na construção do seu discurso, que fornece crenças, valores, opiniões que constituem suas representações sociais e são provenientes da sociedade discursiva da qual faz parte (Bakhtin, 1995; Foucault, 1996; Maingueneau, 1997). Isso auxilia a interpretarmos os motivos que contribuem para que, em determinadas situações da entrevista, as informantes assumam um papel mais pessimista em relação à acessibilidade à natação, pois estão falando a partir do locus social de proprietárias que visam lucrar com o empreendimento; e em outros momentos posicionam-se de forma favorável à viabilização da atividade, através do fornecimento de bolsas para alguns alunos, momento em que tendem a assumir a voz das professoras. 


\section{CONSIDERAÇ̃̃ES FINAIS}

O presente estudo abordou uma variedade de questões referentes às profissionais de Educação Física proprietárias de academias de natação. Ao analisar o discurso das informantes, procurou-se levantar o que se considerou mais relevante para contemplar o objetivo do estudo. Contudo, somos conscientes da impossibilidade de generalizar os resultados inferidos a todos os profissionais proprietários de academias de natação.

Nosso objeto de estudo foi as representações sociais das profissionais proprietárias de academias de natação sobre a possibilidade de acesso à sua prática e sua contribuição na viabilização da natação enquanto atividade de lazer para a comunidade. As informantes representam a natação enquanto atividade de lazer como elitista. No entanto, não desenvolvem projetos de natação para a comunidade em suas respectivas academias, justificando a sua inexistência pela falta de apoio de outros órgãos públicos; pelo preconceito dos demais alunos da academia; e pela falta de educação da classe menos favorecida financeiramente, o que pode causar a evasão de alunos e conseqüente prejuízo para a instituição.

Entretanto, todas as informantes estabelecem um elo com a comunidade através do fornecimento de algumas bolsas para alunos carentes, que apresentem sérios problemas de saúde e possam ser beneficiados pela prática regular da natação.

\section{CONCLUSÕES}

Com este estudo, nosso intuito foi apresentar as representações sociais de um grupo minoritário, professoras de educação física proprietárias de academias de natação, sobre a acessibilidade à prática da natação e a sua função enquanto facilitadoras do processo de viabilização desta atividade para a comunidade.

Diante dos resultados da análise, e da inexistência de projetos que envolvam o ensino da natação para comunidades a partir da iniciativa pública, interpretamos que para a divulgação, valorização e viabilização dos espaços para a prática desportiva como atividade de lazer, é também necessário que os profissionais proprietários de instituições privadas reflitam sobre a possibilidade de assumirem uma postura facilitadora para o desenvolvimento de projetos comunitários, pois sendo donos de suas próprias academias e possuindo a autonomia necessária para tomar decisões, eles se constituem em peças valiosas para que isto se concretize.

\section{REFERÊNCIAS BIBLIOGRÁFICAS}

BAKHTIN, M. Marxismo e Filosofia da Linguagem. São Paulo: Hucitec, 1995.

BETTI, M. Educação Física e Sociedade. São Paulo: Movimento, 1995.

BRAIT, B. (org.). Bakhtin, dialogismo e construção do sentido. Campinas: Unicamp, 1997.

BRAMANTE, A. C. Lazer: concepções e significados. Licere. Belo Horizonte, v. 1, n. 1, p. 9-17. 1998.

BRASIL. SESC. Anais do $5^{\circ}$ Congresso Mundial de Lazer. São Paulo: SESC/WLRA/ALATIR, 1998.

CAMARGO, L. O. C. O que é lazer. São Paulo: Brasiliense, 1992.

CATTEAU, R; GAROFF, G. O Ensino da Natação. São Paulo: Manole, 1990.

CARVALHO, Y. M. de. $O$ "mito" da atividade fisica e saúde. São Paulo: Hucitec, 1995.

COSTA, J. F. Ordem médica e norma familiar. Rio de Janeiro: Graal, 1983.

Pragmática e processo analítico: Freud.

Wittgenstein, Davidson, Rorty. In: COSTA, J. F. (org.). Redescrições da psicanálise. Rio de Janeiro: Relume Dumará. p. 9-59, 1994.

DEVIDE, F. P. Educação física e saúde: em busca de uma reorientação para a sua práxis. Movimento. Porto Alegre, ano III, n. 5, p. 44-55. 1996.

DEVIDE, F. P; FERREIRA, Marcos S. Exercício e saúde: a percepção discente - um estudo exploratório. Revista Brasileira de Atividade Física \& Saúde. Londrina. Ano II, n. 3, p. 5060. 1997.

DUMAZEDIER, J. Lazer e cultura popular. São Paulo: Perspectiva, 1973. 
. Sociologia Empírica do Lazer. São Paulo: Pers pectiva, 1979.

_. Valores e conteúdos culturais do lazer. São Pau lo: SESC, 1980.

_. A revolução cultural do tempo livre. São Paulo: SESC/Studio Nobel, 1994.

FARIA JÚNIOR, A. G. de. Professor de Educação Física, Licenciado Generalista. In: OLIVEIRA, Vítor Marinho de. Fundamentos Pedagógicos Educação Física, vol. 2. Rio de Janeiro: Ao Livro Técnico, 1987.

_. Exercício e Promoção da Saúde. Oeiras: Câ mara Municipal de Oeiras, 1991.

FIORIN, J. L. Linguagem e ideologia. São Paulo: Ática, 1995.

FOUCAULT, M. A ordem do discurso. São Paulo: Loyola, 1996.

JODELET, D. Representations sociales: un domaine en expansion. In: JODELET, D. (org.). Les representations sociales. Paris: PUF. p. 31-61. 1989.

_. A alteridade como produto e processo psicossocial. In: ARRUDA, A. (org.). Representando a alteridade. Petrópolis: Vozes. p. 47-67. 1998.

LENK, M. E. Z. Natação. Rio de Janeiro: Edições Melhoramentos, 1942.

MADEIRA, M. Linguagem e representações sociais: quando a vivência se torna palavra. In: MADEIRA, M. (org.). Representações sociais e educação: algumas reflexões. Natal: EDUFRN. p. 7-21. 1998.

MAINGUENEAU, D. Novas tendências em análise do discurso. Campinas: Pontes/Unicamp, 1997.

MARCELlinO, N. C. Lazer e Educação. São Paulo: Papirus, 1990.

_. Estudos do lazer: uma introdução. São Paulo: Papirus, 1996.

MOSCOVICI, S. A representação social da psicanálise. Rio de Janeiro: Zahar, 1978.

_. Prefácio. In: GUARESCHI, P.; JOVTCHE-

LOVITCH, S. (orgs.). Textos em representações sociais. Petrópolis: Vozes. p. 7-16. 1995.

MOTA, J. A actividade física no lazer: reflexões sobre sua prática. Lisboa: Horizonte, 1997.

ORLANDI, E. P. Discurso e leitura. Campinas: Unicamp, 1996.
PÊCHEUX, M. Semântica e discurso: uma crítica à afirmação do óbvio. Campinas: Unicamp, 1995.

RICHARDSON, R. J. Pesquisa Social: métodos e técnicas. São Paulo: Atlas, 1985.

RORTY, R. Contingência, ironia e solidariedade. Lisboa: Presença, 1994.

ROUQUETTE, M. L. Representações e práticas sociais. In: MOREIRA, A. S. P. \& OLIVEIRA, D. C. de. (orgs.). Estudos interdisciplinares de representação social. Goiânia: AB Editora, p. 27-38. 1998.

SADER, E. Entrevista. Revista E/SESC. São Paulo. v. 5, ii. 4, p. 6-8. 1998.

SOARES, C. L. Educação Física: Raízes Européias no Brasil. São Paulo: Autores Associados, 1994.

SPINK, M. J. O discurso como produção de sentido. In: SCHULZE, C. (org.). Novas contribuições para a terorização e pesquisa em representações sociais. Coletâneas da ANPEPP. Florianópolis: UFSC.v.l.n. 10, p. 9-35, 1996.

WAGNER, W. Sócio-gênese e características das representações sociais. In: MOREIRA, A. S. P. \& OLIVEIRA, D. C. de. (orgs.). Estudos interdisciplinares de representação social. Goiânia: AB Editora, p. 3-25. 1998.

\section{NOTAS}

'Encontra-se, entre os estudiosos do lazer, a utilização de diferentes termos para se denominar aspectos similares. Por exemplo, enquanto Joffre Dumazedier (1973, 1979, 1980) e Luiz Camargo (1992) tratam o tempo fora do trabalho como tempo livre, Nelson Marcellino (1990) o define como tempo disponivel. Da mesma forma, o tempo livre relativo ao desempregado é definido por Dumazedier (1994) como tempo inocupado, enquanto Marcellino (1990) o define como desocupado. Para fins deste estudo, consideramos o 'tempo livre' como aquele fruto da riqueza gerada pela produção, e 'tempo liberado' como aquele no qual, embora o sujeito não esteja trabalhando, não pode escolher o que bem quiser fazer, tal como o período de sono, durante o transporte para o trabalho ou dos afazeres domésticos.

${ }^{2}$ Para saber mais sobre as propriedades educacionais do lazer, ler o estudo de MARCELLINO, Nelson C. (1990). Lazer e Educação. São Paulo: Papirus.

${ }^{3}$ Hoje, por exemplo, habitantes de grandes centros urbanos têm de se deslocar para desfrutar de atividades de lazer em contato com a natureza. Algumas atividades de lazer como, por exemplo, a freqüência em cinemas, teatros e clubes sociais, são inviáveis 
para grande parte da população de baixo poder aquisitivo.

${ }^{4}$ Nos referimos aqui aos processos e condições que Moscovici (1978), associa à gênese das representações sociais, a saber: a ancoragem, a objetivação, o campo de representação, a atitude, a informação, a pressão à inferencia, a focalização e dispersão da informação.

${ }^{5}$ Estas práticas sociais estão representadas no discurso, rituais, trabalho, meios de comunicações de massa etc.

${ }^{6}$ Salientamos que também considerou-se o tempo de trabalho com estágios antes da formatura, uma vez que duas informantes iniciaram o trabalho com aprendizado ainda na graduação.

${ }^{7}$ Para Faria Júnior (1987), o profissional generalista possui conhecimentos humanísticos, é licenciado pleno em Educação Física, tendo permissão legal para atuar em ambientes de ensino formais (escolas) e não formais (clubes, academias, hotéis etc).

${ }^{8} \mathrm{~A}$ maioria das informantes não se identifica com a parte de treinamento. Talvez, isto justifique a atuação em academias, onde predominam as atividades de aprendizado e aperfeiçoamento, questão que necessita maiores investigações.

${ }^{9}$ Estes projetos comunitários poderiam ser desenvolvidos em piscinas como a que foi construída na praia de Copacabana especialmente para sediar um evento internacional.

${ }^{10}$ Centro Integrado de Educação Pública.

${ }^{11}$ As informantes não citam casos em que a pessoas apenas carentes financeiramente freqüentem as aulas. Há de se ter alguma enfermidade para se receber uma bolsa.

\section{UNITERMOS}

Natação; lazer; acessibilidade.

*Fabiano Pries Devide é Mestre em Educação Física e Cultura (UGF/RJ); Doutorando em Educação Física e Cultura/UGF-RJ, na linha de pesquisa de Representações Sociais e Gênero na Educação Fisica, Esporte e Lazer. 